\title{
Efficient destruction of bacteria with Ti(IV) and antibacterial ions in co-substituted hydroxyapatite films
}

\author{
Chun $\mathrm{Hu}^{*}$, Jian Guo, Jiuhui Qu*, Xuexiang $\mathrm{Hu}$ \\ State Key Laboratory of Environmental Aquatic Chemistry, Research Center for Eco-Environmental Sciences, \\ Chinese Academy of Sciences, Beijing 100085, China
}

Received 27 July 2006; received in revised form 11 January 2007; accepted 11 January 2007

Available online 17 January 2007

\begin{abstract}
Hydroxyapatite $\left(\mathrm{Ca}_{10}\left(\mathrm{PO}_{4}\right)_{6}(\mathrm{OH})_{2}\right.$ : HAP) was co-substituted with $\mathrm{Ti}(\mathrm{IV})$ and antibacterial ions $\left(\mathrm{Ag}^{+}, \mathrm{Cu}^{2+}\right.$ or $\left.\mathrm{Zn}^{2+}\right)(\mathrm{HAPTiM})$, by coprecipitation and ion-exchange methods. Both HAPTiAg and HAPTiCu coated on porous spumous nickel film showed high efficiency for killing Escherichia coli and Staphylococcus aureus in the dark and under weak UVA irradiation, respectively. Moreover, their bactericidal activities were much higher than that of $\mathrm{P} 25-\mathrm{TiO}_{2}$ film. The studies of ESR revealed that not only $\mathrm{O}_{2}{ }^{--}$was formed on $\mathrm{HAPTiM}, \mathrm{HAPTi}, \mathrm{HAP}$ and $\mathrm{P} 25-\mathrm{TiO}{ }_{2}$ films under weak UVA irradiation, but also at ambient temperature without light $\mathrm{O}_{2}{ }^{\bullet-}$ was generated on HAPTiCu, HAPTiAg, and HAPTi. The redox couples of $\mathrm{Cu}^{0} / \mathrm{Cu}^{2+}$ and $\mathrm{Ag}^{0} / \mathrm{Ag}^{+}$in the structure of $\mathrm{HAPTiCu}(\mathrm{Ag})$ caused the transfer of electron leading to the $\mathrm{O}_{2}{ }^{--}$generation under the above conditions. The higher bactericidal activities of HAPTiM were due to the synergy of the oxidation role of the $\mathrm{O}_{2}{ }^{\bullet-}$ and the bacteriostatic action of antibacterial ions. The process of the damage of the cell wall and the cell membrane was directly observed by TEM, and further confirmed by the determination of potassium ion $\left(\mathrm{K}^{+}\right)$leakage from the killed bacteria.
\end{abstract}

(C) 2007 Elsevier B.V. All rights reserved.

Keywords: Bacteriostatic action; Bactericidal activity; Hydroxyapatite; Synergistic bactericidal mechanism

\section{Introduction}

In 1985, Matsunaga et al. reported for the first time that $\mathrm{TiO}_{2}$ photocatalyst could kill bacterial cells in water [1]. Since then, numerous studies related to the bactericidal effect of $\mathrm{TiO}_{2}$ photocatalyst have been reported [2-5]. $\mathrm{TiO}_{2}$ photocatalytic disinfection seems to be a promising technique. However, this technique has disadvantages in practical application due to the recovery of $\mathrm{TiO}_{2}$ powder and the high cost of light. Only a few works have reported the use of $\mathrm{TiO}_{2}$ films coated on various substances under weak UV light [6-10]. Moreover, these films showed lower bactericidal activity under weak UV light, which is not effective in real purification. The bactericidal process on $\mathrm{TiO}_{2}$ was investigated by generating decay curves of survival, examining changes in the concentrations of cell envelope components, and taking atomic force microscopy measurements. These data suggest that the bactericidal process consists

\footnotetext{
* Corresponding authors. Tel.: +86106284 9171; fax: +86 1062923541 . E-mail address: huchun@rcees.ac.cn (C. Hu).
}

of two steps [4,11]. Disordering and partially decomposing of the outer membrane in the cell envelope occurs; this is followed by the disordering and decomposing of the inner membrane. To carry out the above reaction, relatively strong UV light is necessary to produce various reactive species from photoexcited $\mathrm{TiO}_{2}$. On the other hand, the antibacterial process using metal ions includes the following steps [6]: first, inorganic ions are taken into the cell through the outer of membrane of the cell; then they make the bacteria inactive by simple bacteriostatic action. For cells having little porous protein in the outer membrane, the bactericidal function of inorganic ions would be disabled [12-14]. It is well known that microorganisms are resistant to many environmental circumstances, and inorganic ions-resistant bacteria arise easily under inorganic ion antibacterial conditions. Therefore, the antibacterial activity of inorganic ions is selective; in some cases, they do not function well. To obtain higher bactericidal activity under weak UV intensity, $\mathrm{TiO}_{2}$ films deposited with antibacterial metals such as copper and silver have been developed [15].

Calcium hydroxyapatite $\mathrm{Ca}_{10}\left(\mathrm{PO}_{4}\right)_{6}(\mathrm{OH})_{2}$ (HAP) is commonly used in the field of bioceramics and as an absorbent for 
liquid chromatography. It has thermal catalytic and photocatalytic properties [16]. Suzuki coworkers have found that $\mathrm{Ca}(\mathrm{II})$ of HAP can be exchanged with various metal ions in aqueous media [17-19]. Some studies has been reported that $\mathrm{Ag}, \mathrm{Cu}$ or $\mathrm{Zn}$ ions were incorporated in HAP and showed obvious antimicrobial effect [20,21]. Wakamura et al. [22] prepared HAP with Ti(IV) by the coprecipitation method, and investigated the photocatalytic activity of this material for the destruction of bacteria and acetaldehyde. However, the bactericidal activity of the material is low; only $1 \log$ bacteria was inactivated. Moreover, the mechanism of the reaction was not proven.

In this work, HAP modified with Ti(IV) (HAPTi) was obtained by coprecipitation method, and inorganic ions $\left(\mathrm{Ag}^{+}\right.$, $\mathrm{Cu}^{2+}$ and $\mathrm{Zn}^{2+}$ ) were incorporated in HAPTi (HAPTiM) by ionexchange method. The HAPTiAg $(\mathrm{Cu})$ coated on porous spumous nickel meshwork showed higher bactericidal activity for Escherichia coli and Staphylococcus aureus in water under weak UV irradiation or in the dark. Electron spin resonance (ESR) was used to detect the reactive oxygen species (ROS) involved in the reactions. For the first time, it was proven that HAPTi, HAPTiAg and HAPTiCu could generated $\mathrm{O}_{2}{ }^{\bullet-}$ at ambient temperatures in the dark in addition to under weak UV irradiation. The mechanisms of killing bacteria were discussed.

\section{Experimental section}

\subsection{Materials}

Titania P-25 $\left(\mathrm{TiO}_{2}\right.$; ca. $80 \%$ anatase, $20 \%$ rutile; BET area, ca. $50 \mathrm{~m}^{2} \mathrm{~g}^{-1}$ ) was purchased from Degussa Co. The reagent 5,5-dimethyl-1-pyrroline- $N$-oxide (DMPO), used as the spin trapping agent in ESR studies, was purchased from the Sigma Chemical Co. and stored at $-20{ }^{\circ} \mathrm{C}$ in a freezer. Superoxide dismutase (SOD) (2500-7000 $\mathrm{U} \mathrm{mg}^{-1}$, Sigma Chemical Co.) was used. E. coli (DH $4 \alpha$ ) and S. aureus (ATCC 6538) were purchased from the Institute of Microbiology, Chinese Academy of Sciences. All other chemicals were analytical grade. Deionized and doubly distilled water was used throughout this study.

\subsection{Preparation of materials}

HAP particles doped with Ti(IV) were prepared by coprecipitation. $\mathrm{Ca}\left(\mathrm{NO}_{3}\right)_{2}$ and $\mathrm{Ti}\left(\mathrm{SO}_{4}\right)_{2}$ were dissolved in 11 deionized-distilled water free from $\mathrm{CO}_{2}$ at atomic ratios $\mathrm{Ti}$ / $(\mathrm{Ca}+\mathrm{Ti}): 0$ and 0.1 . The total amount of $\mathrm{Ca}$ and $\mathrm{Ti}$ in the solution was held at $0.1 \mathrm{~mol} ; 0.060 \mathrm{~mol}$ of $\mathrm{H}_{3} \mathrm{PO}_{4}$ was added to the solutions and the solution $\mathrm{pH}$ was adjusted to 9 by adding a $15 \mathrm{M} \mathrm{NH}_{4} \mathrm{OH}$ solution. The suspension was aged in a capped Teflon vessel at $100{ }^{\circ} \mathrm{C}$ for $6 \mathrm{~h}$. The resulting precipitates were filtered off, washed with 51 deionized-distilled water, and finally dried in an air oven at $70{ }^{\circ} \mathrm{C}$. The HAPTi(IV) $\left(X_{\mathrm{Ti}}=0.1\right)$ particles doped with various inorganic ions including $\mathrm{Ag}^{+}, \mathrm{Cu}^{2+}$ and $\mathrm{Zn}^{2+}$ (HAPTiM), were prepared by ion-exchange method. $0.5 \mathrm{~g}$ samples of the HAPTi particles were immersed in $90 \mathrm{ml}$ of aqueous solutions comprising the metal nitrates at $0.01 \mathrm{M}$.
The suspensions were left at ambient temperature for $24 \mathrm{~h}$, and then the particles were separated by filtration, washed with 1000-1500 ml of deionized-distilled water and dried in an air oven at $70{ }^{\circ} \mathrm{C}$. By ICP-AES analysis, the amounts of $\mathrm{Ag}^{+}$, $\mathrm{Cu}^{2+}$ and $\mathrm{Zn}^{2+}$ incorporated in HAPHTi were 10.23, 6.12 and 5.27 wt. $\%$, respectively. The bactericidal films were prepared by the following method. Suspensions of $0.2 \mathrm{~g}$ powders homogeneously dispersed in silica sols were coated on a round porous spumous nickel meshwork by dip-coating method. The films were dried in an air oven at $100{ }^{\circ} \mathrm{C}$ for $2 \mathrm{~h}$. As a reference, $0.2 \mathrm{~g} \mathrm{P} 25-\mathrm{TiO}_{2}$ power was supported on spumous nickel meshwork by the same process.

\subsection{Characterization}

The series of prepared materials were characterized by various conventional methods as follows. The X-ray diffraction (XRD) patterns were taken by a powder method using a ScintagXDS-2000 X-ray diffractometer Cu K $\alpha 400$ mA, 40 kV. The Xray photoelectron spectroscopy (XPS) data were taken on an AXIS-Ultra instrument from Kratos using monochromatic Al $\mathrm{K} \alpha$ radiation $(225 \mathrm{~W}, 15 \mathrm{~mA}, 15 \mathrm{kV})$ and low-energy electron flooding for charge compensation. To compensate for surface charges effects, binding energies were calibrated using C1s hydrocarbon peak at $284.80 \mathrm{eV}$. Electron spin resonance (ESR) spectra were obtained using a Bruker model ESP 300 E electron paramagnetic resonance spectrometer. For the determination of ROS from irradiated samples, a quanta-ray Nd:YAG laser system as the irradiation light source $(\lambda=355 \mathrm{~nm})$ was used. The settings were center field, $3480.00 \mathrm{G}$; microwave frequency, $9.79 \mathrm{GHz}$; power, $10 \mathrm{~mW}$. For ICP-AES analysis, the powders were dissolved in dilute $\mathrm{HNO}_{3}$ solution.

\subsection{Bacterial experiments}

\subsubsection{Bacterial cultures}

Two types of bacteria, S. aureus, a Gram-positive bacterium, and E. coli, a Gram-negative bacterium, were used as model bacteria in this study. Luria-Bertani (LB) and nutrient agar were used as sources for culturing bacteria at $37{ }^{\circ} \mathrm{C}$ with shaking for $18 \mathrm{~h}$. The culture was washed with a $0.9 \%$ saline solution by centrifugation at $4000 \mathrm{rpm}$. The treated cells were then re-suspended and diluted to $\sim 1 \times 10^{7}$ colony forming units $\left(\mathrm{cfu} \mathrm{ml} \mathrm{m}^{-1}\right.$ ) with $0.9 \%$ saline.

\subsubsection{Bacterial activity of different films}

The bactericidal experiments were performed in an open round glass dish, with an illuminated area of $64 \mathrm{~cm}^{2}$ using $4 \mathrm{~W}$ black light $\left(365 \mathrm{~nm}\right.$ ) with $0.2 \mathrm{~mW} \mathrm{~cm}^{-2}$ (UV R-365). Meanwhile, the same experiments were also carried out in the dark. The model bacteria included E. coli and S. aureus. The diluted cell suspension $30 \mathrm{ml}$ and films were added to the glass plate with a cover. Control experiments included a bacterial suspension without catalyst irradiated by UV, and the bacterial activity of $\mathrm{Ag}^{+}, \mathrm{Cu}^{2+}$, and $\mathrm{Zn}^{2+}$ released from HATiM films. Before and during the light irradiation, an aliquot of the reaction solution was immediately diluted with saline and an 
appropriate dilution of the sample was incubated at $37{ }^{\circ} \mathrm{C}$ for $24 \mathrm{~h}$ on nutrient LB medium, and then the colonies were counted to determine the number of viable cells. For the measurement of $\mathrm{K}^{+}$leakage from the inactive bacteria, at every time interval, $1 \mathrm{ml}$ of the illuminated bacterial suspension was centrifuged and the supernatant for inductively coupled plasma optical emission spectrometry (ICP-OES) analysis was conducted on an OPTIMA 2000 apparatus (Perkin-Elmer Co.). All the above experiments were repeated three times. In the above experiments, $\mathrm{Ag}^{+}, \mathrm{Cu}^{2+}$ and $\mathrm{Zn}^{2+}$ released from HAPTiM films were measured by ICP-OES.

\subsubsection{Transmission electron microscopy (TEM)}

In this experiment, the HAPTiM powder were used because HAPTiM films and HAPTiM powder have same damage for the E. coli, while the HAPTiM power exhibited higher activity than HAPTiM film due to the surface area decrease. In order to check the morphology changes, the high concentration $E$. coli, $10^{8} \mathrm{cfu} \mathrm{ml}^{-1}$ cells were mixed with $0.2 \mathrm{~g} \mathrm{l}^{-1}$ of the prepared powders and the suspension was irradiated. At given time intervals, the cell suspensions were collected and centrifuged down to pellets. For the TEM analysis of E. coli, all samples were prepared according to the following standard procedures [23]. The bacteria pellets were pre-fixed in $2.5 \%$ glutaraldehyde at $4{ }^{\circ} \mathrm{C}$ for $12 \mathrm{~h}$, and then were washed two times with $0.1 \mathrm{M}$ phosphate buffer (PBS) ( $\mathrm{pH}$ 7.2). After washing with PBS, the specimens were rendered by mixing with $2 \%$ $\mathrm{Na}_{2} \mathrm{H}_{5}\left[\mathrm{P}\left(\mathrm{W}_{2} \mathrm{O}_{7}\right)_{6}\right]$ aqueous solution at a volume ratio of $1: 1$ for $2 \mathrm{~h}$. Then the mixed suspensions were dropped onto copper grids with holey carbon film. The grids were dried under natural conditions and examined using a TEM Hitachi H-7500. The same experiments were repeated three times.

\section{Results and discussion}

\subsection{Structure of different prepared materials}

Fig. 1 shows the XRD patterns of different samples. Compared with the characteristic patterns of HAP, HAPTi

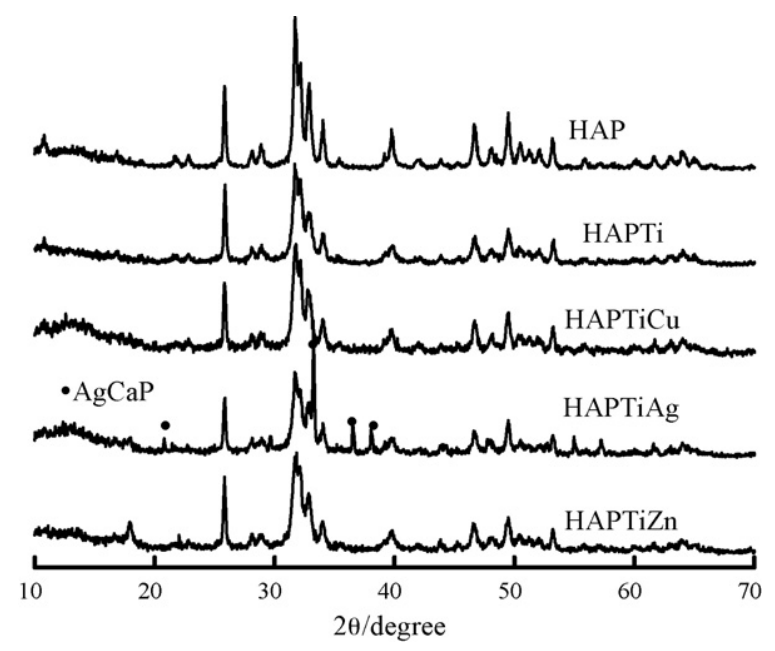

Fig. 1. XRD patterns of different samples.

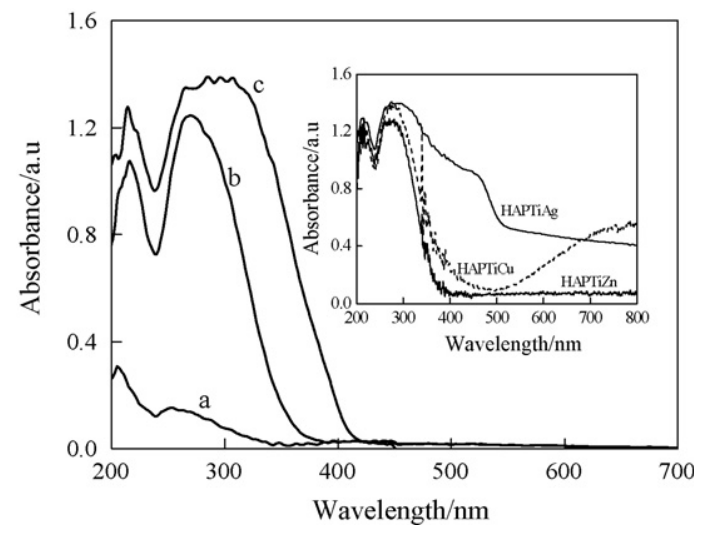

Fig. 2. Diffuse reflection UV-vis spectra of different samples (a) HAP, (b) HAPTi and (c) P25-TiO ${ }_{2}$. The inset shows UV-vis diffuse reflectance spectra of HAPTiM (Ag, $\mathrm{Cu}$ and $\mathrm{Zn})$.

$\left(X_{\mathrm{Ti}}=0.1\right)$ retained well-crystallized HAP. Moreover, the incorporated $\mathrm{Zn}^{2+}, \mathrm{Cu}^{2+}$ and $\mathrm{Ag}^{+}$in HAPTi did not significantly lower the crystallinity of the HAP. XRD patterns showed no significant $\mathrm{Zn}^{2+}$ and $\mathrm{Cu}^{2+}$ in this study. Four new peaks at $20.7^{\circ}$, $33.4^{\circ}, 36.7^{\circ}$ and $38.5^{\circ}$ appeared in the XRD patterns of HAPTiAg, assigned to AgCaP (JCPDS No. 71-1304). A new peaks at $18.2^{\circ}$ appeared in the XRD patterns of HAPTiZn, assigned to $\mathrm{Ca}_{3} \mathrm{Ti}_{2} \mathrm{O}_{7}$ (JCPDS). Fig. 2 illustrates the diffuse reflectance absorption UV-vis spectra of different samples. The UV absorption of HAPTi above $370 \mathrm{~nm}$ is observed, which was similar to that of $\mathrm{P}-25 \mathrm{TiO}_{2}$, but was not observed in the spectrum of the HAP. This result clearly implied that the surface of HAP particles was modified by substitution with Ti(IV). The inset shows the diffuse reflectance absorption UVvis spectra of HAPTi with different metal ions. The additional absorption peaks appear at $400-500 \mathrm{~nm}$ in the spectrum of HAPTiAg, at $500-800 \mathrm{~nm}$ in the spectrum of HAPTiCu, while there is not new peak in the spectrum of HAPTiZn. According to chemical analysis, the atomic ratio of $\mathrm{Ti}(\mathrm{IV})$ to $\mathrm{Ca}(\mathrm{II})$ in HAPTi was around 0.11 -approximately the dosage of Ti(IV) $\left(X_{\mathrm{Ti}}=0.1\right)$. This result means that the Ti(IV) substituted the position of $\mathrm{Ca}(\mathrm{II})$, and was present as a divalent ion leading to oxygen vacancy in the crystal of HAP. With the addition of $\mathrm{Ag}^{+}$, $\mathrm{Cu}^{2+}$ and $\mathrm{Zn}^{2+}$ in the crystal of HAPTi, the Ti(IV) content $\left(1.10 \mathrm{mmol} \mathrm{g}^{-1}\right)$ did not change, but the $\mathrm{Ca}(\mathrm{II})$ content decreased from $8.9 \mathrm{mmol} \mathrm{g}^{-1} \mathrm{Ca}$ (II) in HAPTi to 5.2, 7.4 and $6.8 \mathrm{mmol} \mathrm{g}^{-1} \mathrm{Ca}$ (II) in HAPTiAg, HAPTiCu and HAPTiZn, respectively, indicating that these ions replaced mainly the $\mathrm{Ca}(\mathrm{II})$ of the HAPTi.

\subsection{Bactericidal activity of various films}

The bactericidal activities of the samples were evaluated by the inactivation of E. coli in water. Fig. 3 shows the inactivation of $E$. coli under different control conditions. Clearly, neither HAP film nor HAPTi film under weak UVA irradiation showed any bactericidal effects on E. coli. Additionally, no significant inactivation of $E$. coli was observed under UVA irradiation with no catalyst. E. coli inactivation of $1.8 \mathrm{log}$ occurred at $180 \mathrm{~min}$ of irradiation on $\mathrm{P}_{25}-\mathrm{TiO}_{2}$ films. In contrast, as shown in 


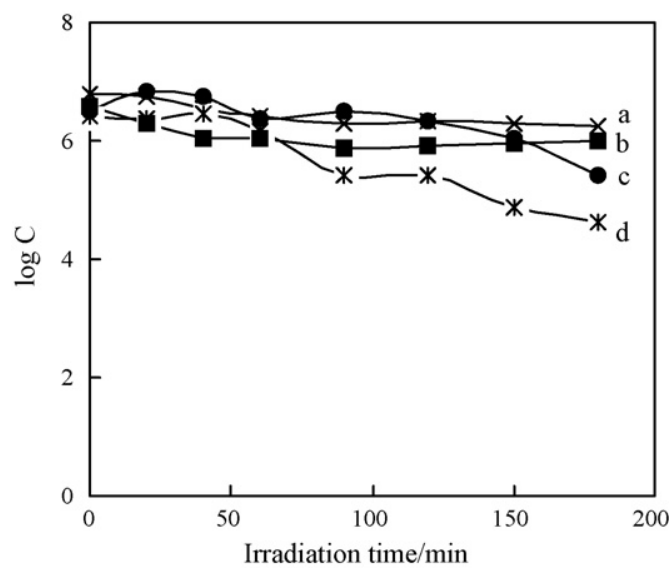

Fig. 3. Temporal course of the E. coli inactivation $\left(5 \times 10^{6} \mathrm{cfu} \mathrm{ml}^{-1}, 30 \mathrm{ml}\right)$ in aqueous solution under UVA irradiation (several control experiments) (a) only UVA irradiation, (b) HAP film, (c) HAPTi film and (d) $\mathrm{P}_{25} 5 \mathrm{TiO}_{2}$ film.

Fig. 4A, E. coli was almost completely killed within 150 min on HAPTiAg films under weak UVA irradiation and in the dark. Complete E. coli inactivation of $6.7 \mathrm{log}$ occurred at $150 \mathrm{~min}$ with or without UVA irradiation. The maximum concentration
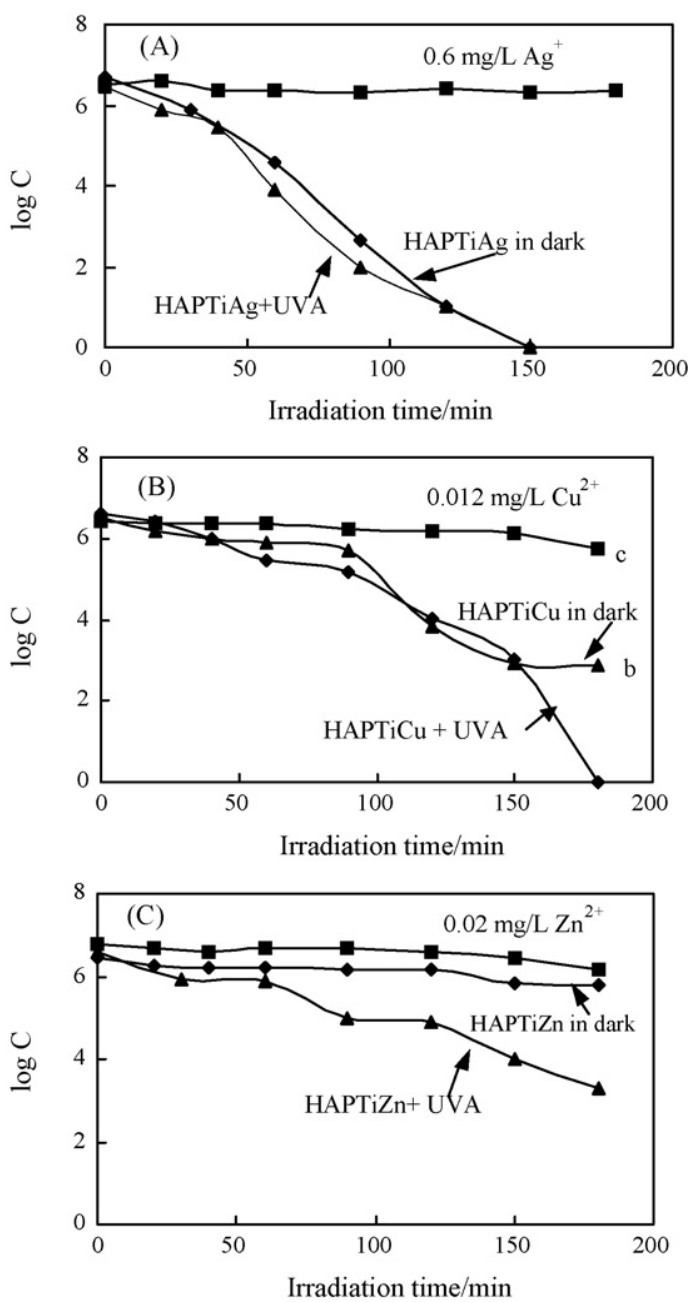

Fig. 4. Temporal course of the E. coli inactivation $\left(5 \times 10^{6} \mathrm{cfu} \mathrm{m}^{-1}, 30 \mathrm{ml}\right)$ in different aqueous solutions: (A) HAPTiAg film, (B) HAPTiCu film, and (C) HAPTiZn film. of $\mathrm{Ag}^{+}$ions leached out into aqueous solution from the HAPTiAg film was about $0.6 \mathrm{mg} \mathrm{l}^{-1}$, which did not show any bactericidal effects on E. coli. Similarly, in the presence of HAPTiCu film, $6.6 \log E$. coli were inactivated at $180 \mathrm{~min}$ irradiation with UVA light $\left(0.2 \mathrm{~mW} \mathrm{~cm}^{-2}\right)$ (Fig. 4B), while $3.6 \log$ E. coli were removed at the same time period in darkness. The maximum $\mathrm{Cu}^{2+}$ ions release was $0.012 \mathrm{mg} \mathrm{l}^{-1}$ from HAPTiCu film with or without UV irradiation. The bactericidal effect of the $\mathrm{Cu}^{2+}$ concentration was not observed, while HAPTiZn showed different performance from HAPTiAg and HAPTiCu. In the presence of HAPTiZn film (Fig. 4C), $3.28 \log E$. coli were inactivated at $180 \mathrm{~min}$ irradiation. Only $0.668 \log E$. coli were removed in the dark, and the released $\mathrm{Zn}^{2+}$ ions $\left(0.02 \mathrm{mg} \mathrm{l}^{-1}\right)$ also did not show any bactericidal
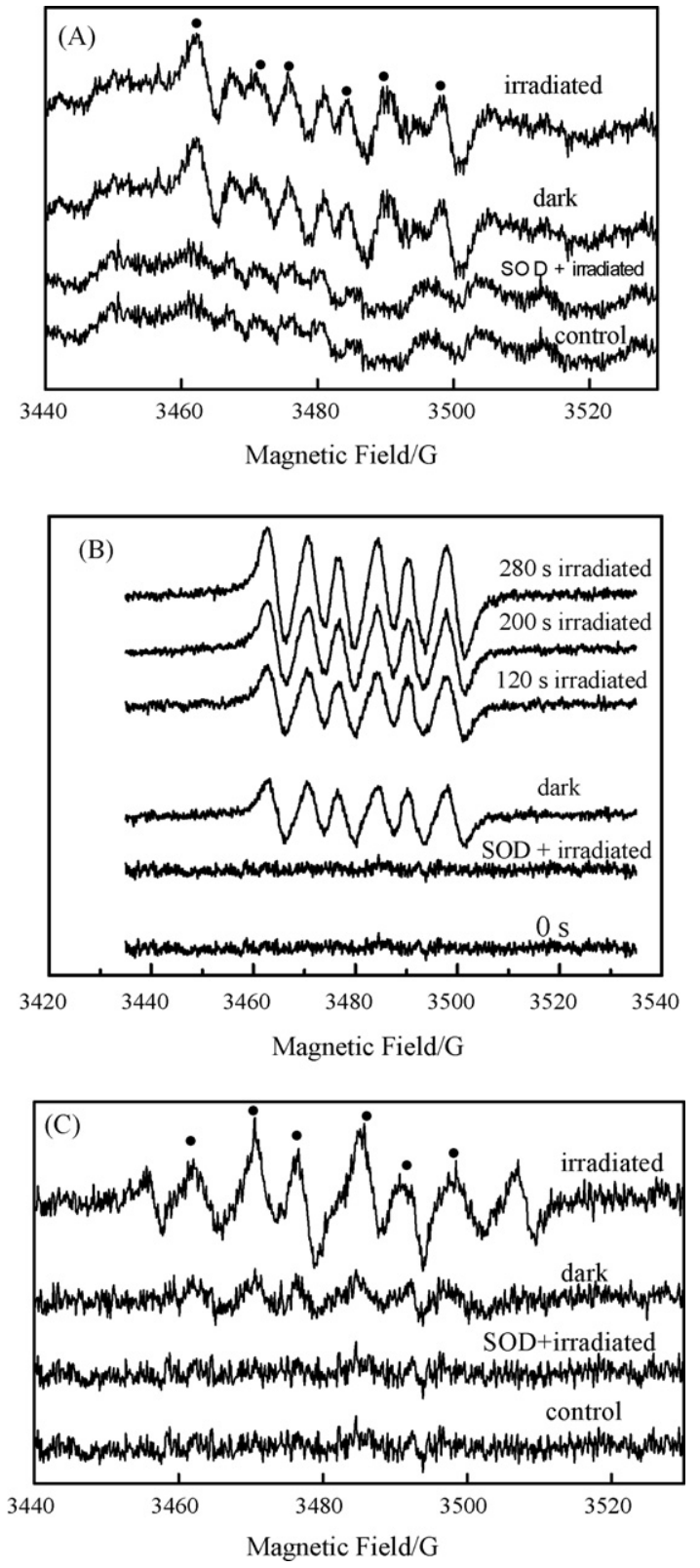

Fig. 5. DMPO spin-trapping ESR spectra recorded at ambient temperature in methanol dispersion under UVA irradiation or in dark, (A) HAPTiAg, (B) HAPTiCu and (C) HAPTi, control: DMPO with UVA irradiation. 
effect on E. coli. Compared with all the above results, the bactericidal activity of HAPTiAg and HAPTiCu films in both UVA and darkness was much higher than that of $\mathrm{P} 25-\mathrm{TiO}_{2}$ film with UVA irradiation, while HAPTiZn showed higher activity only under UVA irradiation. Moreover, the single bacteriostatic action of silver, copper and zinc ions was not observed under otherwise identical conditions. In addition, in the experiment, we found that these HAPTiAg (or $\mathrm{Cu}$ ) films did not show much higher activity under visible light $(\lambda>400 \mathrm{~nm})$ than in the dark, indicating HAPTiAg (or $\mathrm{Cu}$ ) did not visible light-driven activity although they had adsorption of visible light which was mainly contributed to the plasmon resonance of metal. In our another work [24], it has been proved that the adsorption of visible light could not generated reactive oxygen species.
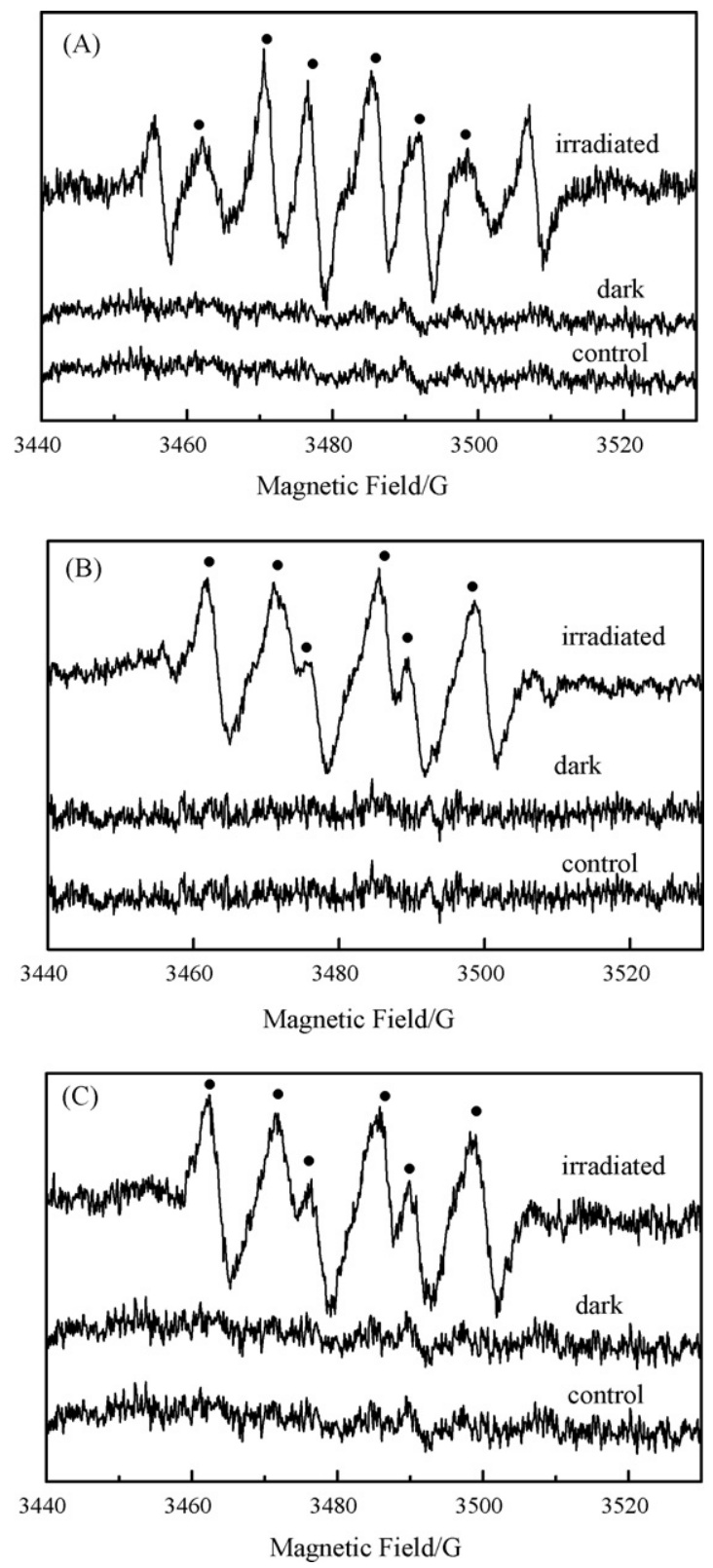

Fig. 6. DMPO spin-trapping ESR spectra recorded at ambient temperature in methanol dispersion under UVA irradiation or in dark (A) $\mathrm{P} 25-\mathrm{TiO}_{2}$, (B) HAP and (C) HAPTiZn, control: DMPO with UVA irradiation.
All the above results indicated that it is quite possible that the $E$. coli was killed by the synergy of the decomposition role of ROS and the bacteriostatic action of these antibacterial ions. To confirm this conjecture, the ESR spin-trap technique (with DMPO) was used to obtain information on the ROS involved in different reactions. Since $\mathrm{O}_{2}{ }^{--}$radicals in water are very unstable and undergo facile disproportionation rather than slow reaction with DMPO $[25,26]$, the involvement of $\mathrm{O}_{2}{ }^{\bullet-}$ radicals in different reaction systems was examined in methanol with an Nd:YAG laser $(355 \mathrm{~nm})$ irradiation source or in the dark. In HAPTiAg, HAPTiCu and HAPTi systems with and without UVA irradiation, six characteristic peaks of the DMPO- $\mathrm{O}_{2}{ }^{--}$adducts were observed (Fig. 5A-C), while in the control system, DMPO with methanol did not exhibit any signal. Furthermore, another control experiment was carried out. Superoxide dismutase (SOD) was added into HAPTiAg, HAPTiCu and HAPTi methanol suspensions in the dark under
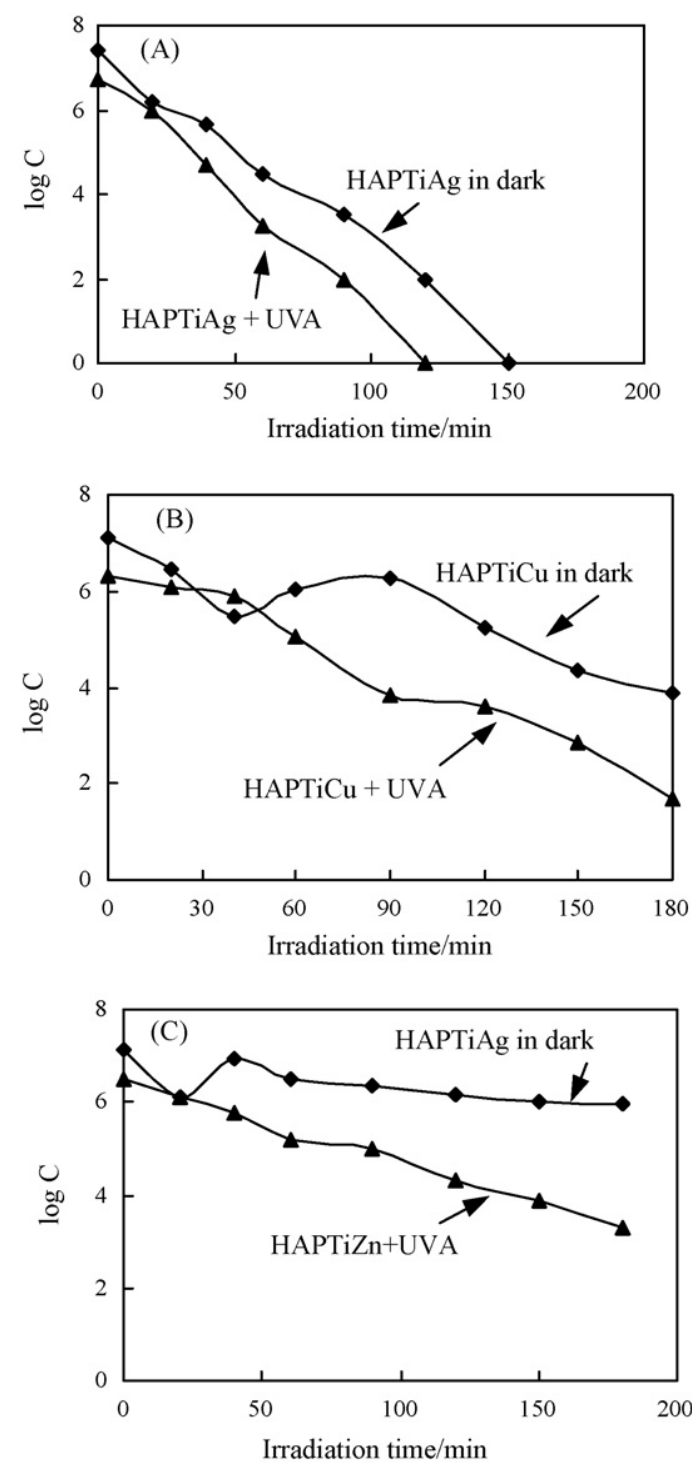

Fig. 7. Temporal course of the $S$. aureus inactivation $\left(5 \times 10^{6} \mathrm{cfu} \mathrm{ml}^{-1}, 30 \mathrm{ml}\right)$ in different aqueous solutions. (A) HAPTiAg film, (B) HAPTiCu film and (C) HAPTiZn film. 
otherwise identical conditions. Obviously, the signal of DMPO- $\mathrm{O}_{2}{ }^{\bullet-}$ adducts were not observed in the control experiment since SOD scavenged $\mathrm{O}_{2}{ }^{\bullet-}$. The results confirmed that $\mathrm{O}_{2}{ }^{\bullet-}$ radicals were generated from HAPTiAg, HAPTiCu and HAPTi systems in the dark. For the P25- $\mathrm{TiO}_{2}, \mathrm{HAP}$, and HAPTiZn systems (Fig. 6A-C), six characteristic peaks of the DMPO- $\mathrm{O}_{2}{ }^{\bullet-}$ adducts were observed under UV irradiation, but no such signals were detected in the dark. The results verified that HAPTiAg, HAPTiCu, and HAPTi can generate $\mathrm{O}_{2}{ }^{\bullet-}$ both under UVA irradiation and in the dark, while other materials have to be excited by UV light and then $\mathrm{O}_{2}{ }^{\bullet-}$ is generated. Therefore, in the dark, HAP and $\mathrm{P} 25-\mathrm{TiO}_{2}$ films had no bactericidal activity, whereas HAPTi did not show any obvious effect either due to the little intensity of the DMPO$\mathrm{O}_{2}{ }^{\bullet-}$. HAPTiZn film only had bacteriostatic action in this case, causing no significant inactivation of $E$. coli. However, in both the HAPTiAg and HAPTiCu film systems, E. coli not only was decomposed by $\mathrm{O}_{2}^{\bullet-}$, but also was inhibited by silver or copper ions, causing faster inactivation in the dark. Similarly, under UV irradiation, both HAPTiAg and HAPTiCu films had the same role as that in the dark, and the more $\mathrm{O}_{2}{ }^{\bullet-}$ was formed due to UV irradiation, the more inactivation of $E$. coli occurred. In the same case, HAPTiZn film also had both oxidation and antibacterial activity, causing higher inactivation of $E$. coli. In contrast, HAP, HAPTi and P$25 \mathrm{TiO}_{2}$ only had the function of decomposing bacteria under UVA irradiation. Since the tested UVA intensity was relatively weak, the amount of $\mathrm{O}_{2}{ }^{\bullet-}$ formed from HAP and HAPTi was too small to lead to any obvious E. coli inactivation. However, the intensity of $\mathrm{O}_{2}^{\bullet-}$ from $\mathrm{P}-25 \mathrm{TiO}_{2}$ was stronger than that from HAP and HAPTi, and some $E$. coli inactivation was observed. Nevertheless, the bactericidal activity of $\mathrm{P}-25 \mathrm{TiO}_{2}$ was still much lower than that of HAPTiM. The results demonstrated that the synergistic effect
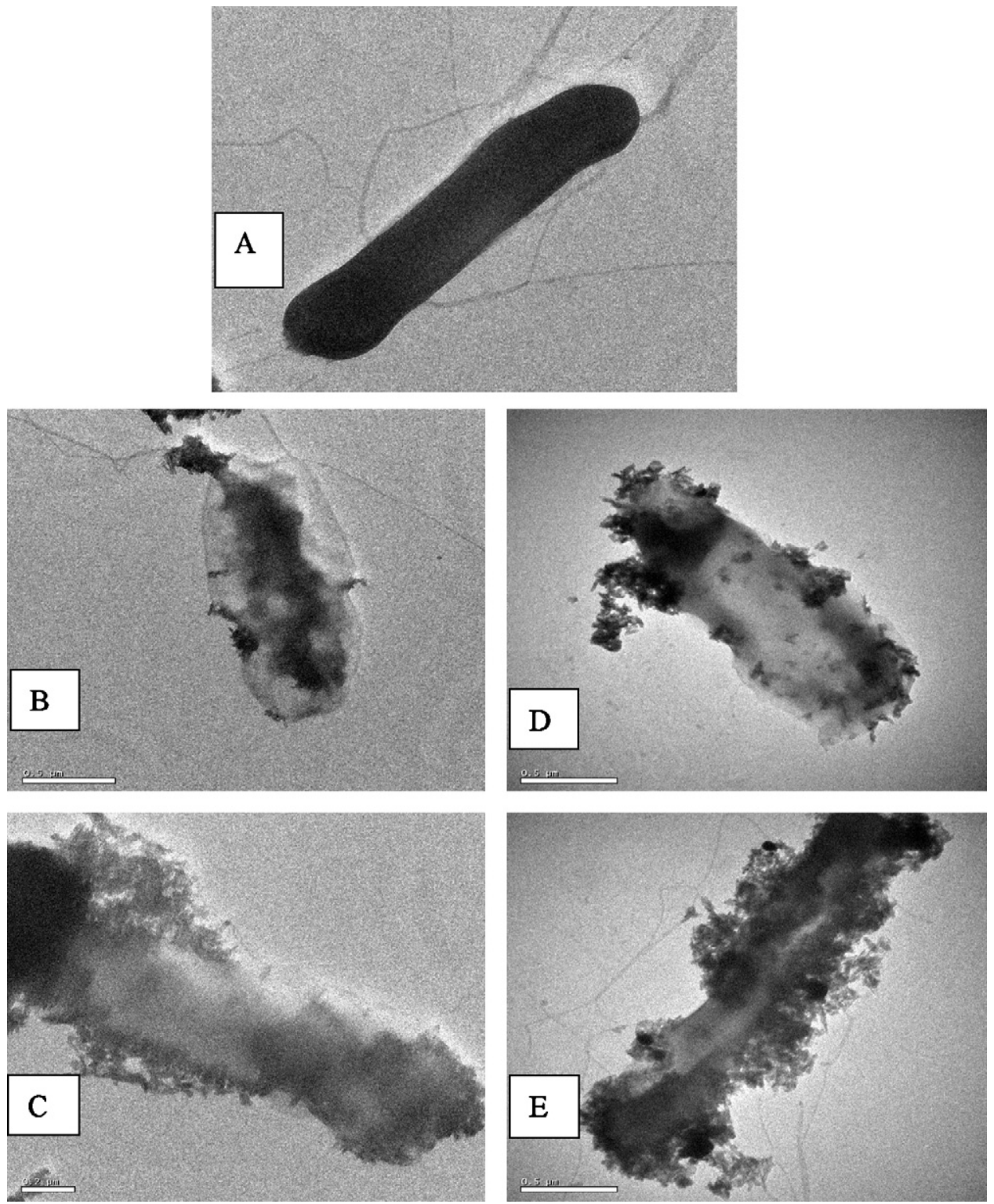

Fig. 8. (A) E. coli-not treated, (B and C) TEM micrographs of E. coli in UVA illuminated HAPTiAg suspension for $2 \mathrm{~h}$ and (D and E) TEM micrographs in HAPTiAg suspension in the dark for $5 \mathrm{~h}$. 
of the oxidation reaction and antibacterial reaction was much greater than that of their sum. As shown in Fig. 7A-C, $S$. aureus was also killed efficiently on HAPTiAg and HAPTiCu films, respectively, under UVA irradiation or in the dark. The complete $S$. aureus inactivation of $6.7 \mathrm{log}$ and $7.3 \mathrm{log}$ occurred at 120 and $150 \mathrm{~min}$ on HAPTiAg films with and without UVA irradiation, while $4.65 \log S$. aureus and $3.2 \log$ $S$. aureus were inactivated at $180 \mathrm{~min}$ on HAPTiCu film with or without UVA, respectively. $1.2 \log S$. aureus were inactivated at $180 \mathrm{~min}$ on HAPTiZn film in the dark due to the bacteriostatic action of zinc ions, while $3.2 \log S$. aureus inactivation occurred on HAPTiZn film with UVA irradiation for the same time period (Fig. 7C). As expected, HAP and HAPTi films still did not exhibit any significant bactericidal activity for $S$. aureus, while only about $1 \log S$. aureus was inactivated on $\mathrm{P} 25-\mathrm{TiO}_{2}$ film under weak UVA irradiation (data not shown here).

\subsection{A possible mechanism of HAPTiAg $(\mathrm{Cu})$ generating $\mathrm{O}_{2}{ }^{\bullet-}$ in the dark}

It has been reported $[27,28]$ that the radical $\mathrm{O}_{2}{ }^{\bullet-}$ could be formed on HAP by heat treatment or UV irradiation. The main mechanism for radical $\mathrm{O}_{2}{ }^{\bullet-}$ formation on $\mathrm{HAP}$ has been proposed. The UV irradiation or heat treatment causes the changes of the surface $\mathrm{PO}_{4}$ group, probably the formation of an oxygen vacancy, which traps the electrons, leading to the formation of the $\mathrm{O}_{2}{ }^{\bullet-}$ species [28]. In the present study, HAPTi HAPTiAg $(\mathrm{Cu})$ could generate $\mathrm{O}_{2}{ }^{\bullet-}$ species at room temperature without UV irradiation. Moreover, the intensity of $\mathrm{O}_{2}{ }^{\bullet-}$ signals formed in HAPTiAg $(\mathrm{Cu})$ was stronger than that in HAPTi. Particularly, the highest intensity of $\mathrm{O}_{2}{ }^{\bullet-}$ signals was observed in HAPTiCu. Based on the structure characterization of HAPTi and HAPTiAg(Cu), Ti(IV), $\mathrm{Ag}^{+}, \mathrm{Cu}^{2+}$ and $\mathrm{Zn}^{2+}$ all substituted the $\mathrm{Ca}(\mathrm{II})$ in the crystal of HAP. It is quite possible
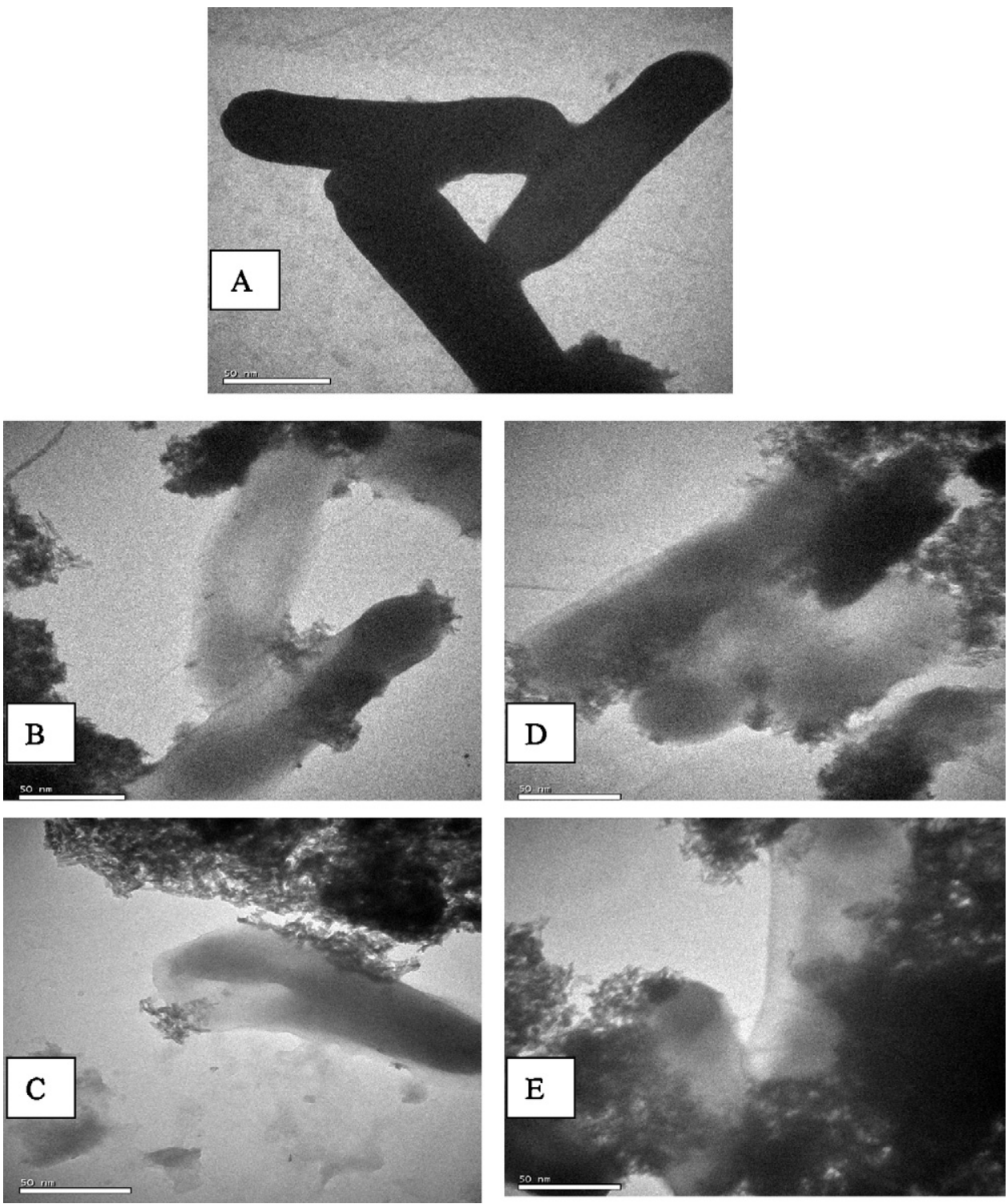

Fig. 9. (A) E. coli-not treated, (B and C) TEM micrographs of E. coli in UVA illuminated HAPTiCu suspension for $2 \mathrm{~h}$ and (D and E) TEM micrographs in HAPTiCu suspension without light for $5 \mathrm{~h}$. 
that the substitution of Ti(IV) caused the oxygen vacancy in the crystal of HAP because the valency of Ti(IV) is higher than that of $\mathrm{Ca}(\mathrm{II})$. The formation of the oxygen vacancy was attributed to the possible formation of $\mathrm{O}_{2}{ }^{\bullet-}$ at ambient temperature. Furthermore, HAPTiAg and HAPTiCu were characterized by XPS. The $\mathrm{Cu} 2 \mathrm{p} 3$ binding energy (BE) was $932.73 \mathrm{eV}$ assigned to $\mathrm{Cu}^{0}, 934.49 \mathrm{eV}$ assigned to $\mathrm{Cu}^{2+}$, respectively. Also the silver species mainly exists as $\mathrm{Ag}^{0}$ (BE: $367.82 \mathrm{eV}$ )and $\mathrm{Ag}^{+}$(BE: $367.55 \mathrm{eV})$. Thus, the redox couples $\mathrm{Cu}^{0} / \mathrm{Cu}^{2+}$ and $\mathrm{Ag}^{0} / \mathrm{Ag}^{+}$ were formed in the structure of HAPTiCu and HAPTiAg, respectively. In the presence of oxygen, the $\mathrm{O}_{2}{ }^{\bullet-}$ could be generated by the electron transfer of the redox couple, which is agreed with the reported work [29]. No $\mathrm{Zn}^{0}$ was formed in the structure of HAPTiZn by XPS analysis, the redox couple $\mathrm{Zn}^{\circ}$ \% $\mathrm{Zn}^{2+}$ did not occur. Therefore, the $\mathrm{O}_{2}{ }^{\bullet-}$ could not be generated in HAPTiZn in the dark.

\subsection{Cell damage mechanism}

Fig. 8 shows the transmission electron microscopy (TEM) findings for $E$. coli after different treatment of HAPTiAg films with or without UVA irradiation. Fig. 8A shows the appearance of $E$. coli before the reaction. The characteristics of the E. coli are a well-defined cell wall as well as the rendered interior of the cell, which corresponds to the presence of proteins and DNA. Great changes had taken place to the morphology of $E$. coli that had been illuminated for $150 \mathrm{~min}$ (Fig. 8B-C). The cell wall was decomposed and the rendered interior of the cell became white, indicating that the outer membrane of the cell was damaged leading to leakage of the interior component. Similarly, the cell wall of $E$. coli was also destructed resulting in leakage of the interior component (Fig. 8D-E) in the dark with HAPTiAg film. Fig. 9A-E also shows the cell damage process of the E. coli on HAPTiCu film with or without UVA irradiation, indicating the E. coli also was killed and disrupted on HAPTiCu film due to the synergistic effect of the oxidation of $\mathrm{O}_{2}{ }^{\bullet-}$ and the antibacterial action of copper ions. Based on the TEM investigation, the cell wall, the peptidoglycan layer and the cell membrane of the bacteria were decomposed by $\mathrm{O}_{2}{ }^{\bullet-}$. In order to determine the change in cell membrane permeability, $\mathrm{K}^{+}$leakage from $E$. coli cells was examined. Under only UVA irradiation or in the presence of $0.6 \mathrm{mg} \mathrm{l}^{-1}$ silver ions (Fig. 10A), the $\mathrm{K}^{+}$leakage was slow. After the addition of HAPTiAg film with or without UVA irradiation, $\mathrm{K}^{+}$ immediately started to leak from the E. coli cells and the leakage gradually increased with reaction time, paralleling the loss of cell viability. The resultant $\mathrm{K}^{+}$concentrations were much higher than that of the control experiments. Moreover, the amount of the $\mathrm{K}^{+}$leakage was almost equal under the two conditions, indicating that the cell membrane was damaged to the same extent with or without UVA irradiation. The $\mathrm{K}^{+}$ leakage was also determined for $\mathrm{HAPTiCu}$ film with and without UVA (Fig. 10B). At $0.012 \mathrm{mg} \mathrm{l}^{-1}$ copper ions, the $\mathrm{K}^{+}$ leaked from the cells slowly, and much less $\mathrm{K}^{+}$leaked compared to the HAPTiCu film system, where $\mathrm{K}^{+}$immediately leaked out and the leakage increased in parallel with the inactivation of $E$. coli with reaction time. Also, there was
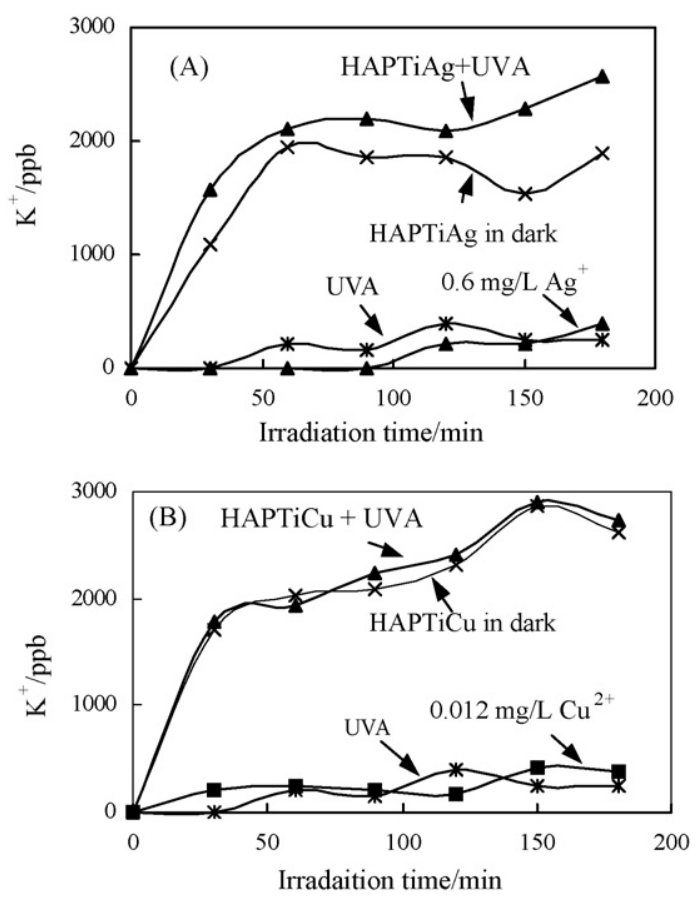

Fig. 10. Leakage of $\mathrm{K}^{+}$from $E$. coli cells in different aqueous solutions (A) HAPTiAg film and (B) HAPTiCu film.

nearly same $\mathrm{K}^{+}$leakage from $E$. coli cells in both UVA and in the dark. These results demonstrate that the $\mathrm{K}^{+}$leakage was consistent with the disruption of the cell wall and the cell membrane by the oxidation and antibacterial action. In the bactericidal process of HAPTiAg and HAPTiCu, Ti(IV) and $\mathrm{Ag}^{+}\left(\mathrm{Cu}^{2+}\right)$ ions assist each other. On the one hand, the outer membrane of the cell is attacked by $\mathrm{O}_{2}{ }^{\bullet-}$ produced from HAPTiAg $(\mathrm{Cu})$. Successively, $\mathrm{Ag}^{+}\left(\mathrm{Cu}^{2+}\right)$ ions are effectively taken into the cytoplasmic membrane by the partially decomposed outer membrane. Finally, the bacteria are inactivated by the bacteriostatic action of $\mathrm{Ag}^{+}$or $\mathrm{Cu}^{2+}$. On the other hand, the bacteriostatic action of these ions enhances the efficiency of $\mathrm{O}_{2}{ }^{--}$in killing bacteria.

\section{Conclusions}

Ti(IV) and antibacterial ions co-substituted hydroxyapatite (HAPTiM) was prepared by a coprecipitation and ion-exchange methods. HAPTiAg and HAPTiCu coated on porous spumous nickel film showed high efficiency for killing of $E$. coli and $S$. aureus in dark and under weak UVA irradiation. For the first time, the studies of ESR proved that $\mathrm{O}_{2}{ }^{\bullet-}$ radicals were formed on HAPTiCu, HAPTiAg and HAPTi in the dark at ambient temperature. XPS results indicated that the interactions between the redox couple of $\mathrm{Cu}^{0} / \mathrm{Cu}^{2+}$ or $\mathrm{Ag}^{0} / \mathrm{Ag}^{+}$and $\mathrm{O}_{2}$ possibly resulted in the $\mathrm{O}_{2}{ }^{\bullet-}$ formation. Moreover, HAPTiM, HAPTi, HAP and $\mathrm{P} 25-\mathrm{TiO}_{2}$ also generated $\mathrm{O}_{2}{ }^{\bullet-}$ radicals under weak UVA irradiation. The high bactericidal activities of HAPTiM were due to the synergy of the oxidation role of the $\mathrm{O}_{2}{ }^{\bullet-}$ and the bacteriostatic action of antibacterial ions. Furthermore, The damage process of the cell was shown by TEM and the determination of $\mathrm{K}^{+}$leakage. 


\section{Acknowledgments}

This work was supported by the Natural Science Foundation of China (Grant Nos. 20577062, 20537020, 50621804 and 50538090) and the National 863 Project of China (Grant No. 2006AA06Z304).

\section{References}

[1] T. Matsunaga, R. Tomada, T. Nakajima, H. Wake, FEMS Microbiol. Lett 29 (1985) 211.

[2] W.A. Jacoby, C.P. Maness, E.J. Wolfrum, D.M. Blake, J.A. Fennel, Environ. Sci. Technol. 32 (1998) 2650.

[3] G. Fu, P.S. Vary, C.T. Lin, J. Phys. Chem. B 109 (2005) 8889.

[4] K. Sunada, Y. Kikuchi, K. Hashimoto, A. Fujishima, Environ. Sci. Technol. 32 (1998) 726.

[5] J.C. Yu, W. Ho, J. Yu, H. Yip, P.K. Wong, J. Zhao, Environ. Sci. Technol. 39 (2005) 1175

[6] K. Sunada, T. Watanabe, K. Hashimoto, Environ. Sci. Technol. 37 (2003) 4785.

[7] A. Fujishima, T.N. Rao, D.A. Tryk, J. Photochem. Photobiol. C: Photochem. Rev. 1 (2000) 1.

[8] J.C. Yu, W.K. Ho, J. Lin, H. Yin, P.K. Wong, Environ. Sci. Technol. 37 (2003) 2296.

[9] K. Ishibashi, A. Fujishima, T. Watanabe, K. Hashimoto, J. Phys. Chem. B 104 (2000) 4934.

[10] K. Ishibashi, A. Fujishima, T. Watanabe, K. Hashimoto, J. Photochem. Photobiol. A: Chem. 134 (2000) 139.
[11] K. Sunada, T. Watanabe, K. Hashimoto, J. Photochem. Photobiol. A: Chem. 156 (2003) 227.

[12] J.F. Lutkenhaus, J. Bacteriol. 131 (1977) 631.

[13] H. Nikaido, E.Y.J. Rosenberg, J. Bacteriol. 153 (1983) 241.

[14] R. Benz, A. Schmid, R.E.W. Hancock, J. Bacteriol. 162 (1985) 722.

[15] TOTO Ltd., Patent No. (PCT) WO95/15816, 11 (1995) 175.

[16] H. Monma, J. Catal. 75 (1982) 200.

[17] M. Miyake, K. Ishigaki, T. Suzuki, J. Solid State Chem. 61 (1986) 230 .

[18] Y. Tanizawa, K. Sawamura, T. Suzuki, J. Chem. Soc. Faraday Trans. 86 (1990) 1071.

[19] Y. Tanizawa, K. Sawamura, T. Suzuki, J. Chem. Soc. Faraday Trans. 86 (1990) 4025.

[20] R. Chung, M. Hsieh, C. Huang, L. Perng, H. Wen, T. Chin, J. Biomed. Mater. Res. B: Appl. Biomater. 76 (2006) 169.

[21] T.N. Kim, Q.L. Feng, J.O. Kim, J. Wu, H. Wang, G.C. Chen, F.Z. Cui, J. Mater. Sci.: Mater. Med. 9 (1998) 129.

[22] M. Wakamura, K. Hashimoto, T. Watanabe, Langmuir 19 (2003) 3428.

[23] P. Shen, X. Fan, G. Li, Microbiological Experiment, Higher Education Press, Beijing, 2004

[24] C. Hu, Y. Lan, J. Qu, X. Hu, A. Wang, J. Phys. Chem. B 110 (2006) 4066.

[25] D.T. Sawyer, J.S. Valentine, Acc. Chem. Res. 14 (1981) 393.

[26] W. Ma, Y. Huang, J. Li, M. Chen, W. Song, J. Zhao, Chem. Commun. (2003) 1582.

[27] H. Nishikawa, J. Mol. Catal. A: Chem. 206 (2003) 331.

[28] Y. Matsumura, H. Kanai, J.B. Moffat, J. Chem. Soc. Faraday Trans. 93 (1997) 4383.

[29] S.H. Joo, A.J. Feitz, T.D. Waite, Environ. Sci. Technol. 38 (2004) 2242. 